\title{
A EXCLUSÃO DA TEMÁTICA SEXUALIDADE NOS ANOS INICIAS DO ENSINO FUNDAMENTAL NA BNCC E SEUS REFLEXOS PARA O ENSINO DE CIÊNCIAS
}

\author{
THE EXCLUSION OF SEXUALITY THEME IN THE BEGINNINGS OF \\ FUNDAMENTAL EDUCATION IN BNCC AND ITS REFLEXES FOR SCIENCE \\ TEACHING
}

Ricardo DESIDÉRIO ${ }^{1}$

\begin{abstract}
Resumo: O Ensino de Ciências nos Anos Iniciais do Ensino Fundamental na nova Base Nacional Comum Curricular (BRASIL, 2018) inicialmente se destaca pelo compromisso do letramento científico, da abordagem investigativa, e também, da progressão de aprendizagem. No entanto, no que se refere as temáticas da sexualidade, as mesmas foram excluídas dos Anos Iniciais do Ensino Fundamental. Contudo, numa tentativa de elencar os reflexos dessa exclusão, o texto apresenta direcionamentos para este trabalho em sala de aula, evidenciando a necessidade do compromisso de um trabalho efetivo e sistemático para além do que nos foi vetado no/para o Ensino de Ciências e demais áreas do conhecimento.
\end{abstract}

Palavras-chave: Ensino de Ciências. Anos Iniciais do Ensino Fundamental. Sexualidade. Educação Sexual.

\begin{abstract}
Science Teaching in the Early Years of Elementary Education in the new National Common Curricular Base (BRASIL, 2018) initially stands out for its commitment to scientific literacy, the investigative approach, and also, the progression of learning. However, with regard to the themes of sexuality, they were excluded from the Early Years of Elementary Education. However, in an attempt to list the consequences of this exclusion, the text presents guidelines for this work in the classroom, highlighting the need for a commitment to effective and systematic work beyond what was forbidden in/for Science Education and others knowledge areas.
\end{abstract}

Keywords: Science Teaching. Elementary School. Sexuality. Sex Education.

\section{Introdução}

O ensino de Ciências da Natureza possui uma curta história na educação brasileira. Até a promulgação da Lei de Diretrizes e Bases da Educação (LDB) de 1961, era ofertada apenas

\footnotetext{
${ }^{1}$ Doutor e Pós-doutor em Educação Escolar. Docente do Curso de Pedagogia da Universidade Estadual do ParanáUNESPAR, Campus de Apucarana-PR e do Programa de Mestrado em Educação Sexual da Unesp/AraraquaraSP. E-mail: contatodesiderio@ hotmail.com
} 


\section{HORIZONTES - REVISTA DE EDUCACATO}

nas duas últimas séries do antigo curso ginasial, e somente após a Lei n 5.692/1971 é que foi ampliado para todo o Ensino Fundamental, com uma abordagem metodológica bastante tradicional (BRASIL, 1997).

No entanto, a partir da década de 90, com a chegada dos PCN (BRASIL, 1997), as atividades práticas começam a surgir, deixando de lado - ao menos num grande esforço, o método tradicional e essa nova abordagem, passou a ser utilizada de forma sistemática nos projetos curriculares de todas as disciplinas, incluindo Ciências, com ênfase maior na vivência do método cientifico, o que proporcionaria ao aluno por meio da investigação, a observação de fatos e fenômenos, a criação de hipóteses e a chegada a conclusões.

Assim, as propostas educativas enfatizavam a necessidade de levar os estudantes a desenvolverem o pensamento reflexivo e crítico, a questionarem as relações existentes entre a ciência, a tecnologia, a sociedade e o meio ambiente e a se apropriarem de conhecimentos científico, social e culturalmente relevantes (DELIZOICOV, ANGOTTI e PERNAMBUCO, 2009). Entretanto, ainda que "o método científico fosse um pressuposto educativo amplamente aceito no cenário educacional, foram grandes as dificuldades de formação e treinamento de professores, principalmente no sentido de levá-los a implementar determinadas propostas educativas" (NASCIMENTO, FERNANDES e MENDONÇA, 2010, p. 230), pois rompiam diretamente com o velho método tradicional e colocava o aluno como sujeito ativo de todo processo.

Resumidamente, em 2015 o MEC institui (Portaria no. 592), junto com o Consed (Conselho Nacional de Secretários de Educação) e a Undime (União Nacional dos Dirigentes Municipais de Educação) um grupo de redação, que seria responsável pela elaboração da BNCC, documento

de caráter normativo que define o conjunto orgânico e progressivo de aprendizagens essenciais que todos os alunos devem desenvolver ao longo das etapas e modalidades da Educação Básica, de modo a que tenham assegurados seus direitos de aprendizagem e desenvolvimento, em conformidade com o que preceitua o Plano Nacional de Educação (PNE) (BRASIL, 2018).

Com isso, em setembro do mesmo ano a primeira versão vai para consulta pública. Assim, com a consulta online da primeira versão encerrada, Consed e Undime levam a segunda versão para todo país, em meados de 2016. 


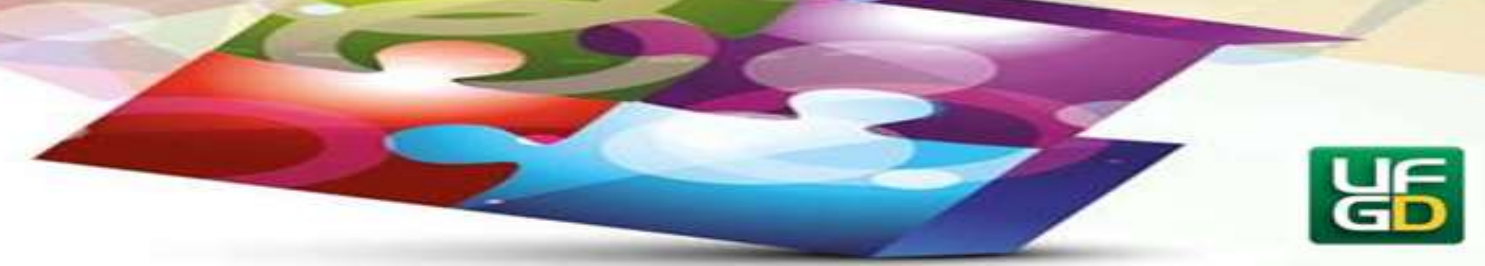

Já em abril de 2017, após seminários estaduais, MEC entrega ao Conselho Nacional de Educação a terceira versão da BNCC, que veio a público com as partes da Educação Infantil e do Ensino Fundamental. No entanto, carentes de um diálogo mais preciso, já que entre junho a setembro o CNE promoveu as audiências públicas, e que vale aqui lembrar, foram de difícil acesso, o documento é aprovado e homologado pelo Ministro da Educação em dezembro do mesmo ano.

Nas palavras de Mendonça Filho, então Ministro da Educação, a BNCC

expressa o compromisso do Estado Brasileiro com a promoção de uma educação integral voltada ao acolhimento, reconhecimento e desenvolvimento pleno de todos os estudantes, com respeito às diferenças e enfrentamento à discriminação e ao preconceito. Assim, para cada uma das redes de ensino e das instituições escolares, este será um documento valioso tanto para adequar ou construir seus currículos como para reafirmar o compromisso de todos com a redução das desigualdades educacionais no Brasil e a promoção da equidade e da qualidade das aprendizagens dos estudantes brasileiros (BRASIL, 2018, p. 5, grifos nosso).

Contudo, com tamanha preocupação nas palavras de Mendonça Filho no que se refere ao respeito às diferenças e enfrentamento à discriminação, ao preconceito, assim como na adequação e até mesmo construção de seus currículos, a temática da sexualidade, tão diretamente ligada a todos estes compromissos listados por ele, simplesmente é retirada de pauta nas discussões para o Ensino de Ciências dos Anos Iniciais do Ensino Fundamental e de toda BNCC.

Assim, este estudo caracteriza-se por uma pesquisa qualitativa-descritiva, do tipo documental, que teve por objetivo discorrer sobre a exclusão da temática sexualidade nos Anos Iniciais do Ensino Fundamental na BNCC, elencando assim os seus reflexos para o Ensino de Ciências.

\section{Ciências da Natureza, sexualidade e BNCC}

Se pensarmos o Ensino de Ciências nos Anos Iniciais do Ensino Fundamental e a Base Nacional Comum Curricular (BRASIL, 2018), a mesma se destaca no compromisso de levar para sala de aula 
[...] o desenvolvimento do letramento científico, que envolve a capacidade de compreender e interpretar o mundo (natural, social e tecnológico), mas também de transformá-lo com base nos aportes teóricos e processuais das ciências.

Em outras palavras, apreender ciência não é a finalidade última do letramento, mas, sim, o desenvolvimento da capacidade de atuação no e sobre o mundo, importante ao exercício pleno da cidadania.

Nessa perspectiva, a área de Ciências da Natureza, por meio de um olhar articulado de diversos campos do saber, precisa assegurar aos alunos do Ensino Fundamental o acesso à diversidade de conhecimentos científicos produzidos ao longo da história, bem como a aproximação gradativa aos principais processos, práticas e procedimentos da investigação científica (BRASIL, 2018, p. 319).

Assim, o objetivo do documento é claro, evidenciando o seu compromisso em proporcionar aos alunos o contato com processos, práticas e procedimentos da investigação científica para que eles sejam capazes de atuarem no e sobre o mundo. Além disso, nele, destaca-se também três unidades temáticos (Matéria e Energia; Vida e Evolução; e Terra e Universo) que organizam os conteúdos do componente curricular e que nos PCN (BRASIL, 1997) eram chamados de blocos temáticos (Ambiente, Ser humano e saúde; Recursos tecnológicos; e Terra e Universo).

No entanto, alinhado as três unidades temáticas que se repetem ano a ano, a Ciências da Natureza é então estruturada em um conjunto de habilidades cuja complexidade cresce progressivamente em uma distribuição mais equilibrada entre conteúdos tradicionais do componente curricular, não sendo mais fragmentada como antes, como por exemplo, as áreas de Física e Química que ficavam sempre no final dos Anos Finais do Ensino Fundamental. Com essa nova distribuição, as unidades temáticas são trabalhadas em todos os anos, o que é um grande avanço.

Neste texto, tomaremos aqui como base a unidade temática Vida e Evolução, que engloba o estudo diretamente relacionado aos seres vivos e que, é o eixo que abordaria as questões da sexualidade nos Anos Inicias do Ensino Fundamental mais especificamente.

Segundo o documento, este eixo 
propõe o estudo de questões relacionadas aos seres vivos (incluindo os seres humanos), suas características e necessidades, e a vida como fenômeno natural e social, os elementos essenciais à sua manutenção e à compreensão dos processos evolutivos que geram a diversidade de formas de vida no planeta. Estudam-se características dos ecossistemas destacando-se as interações dos seres vivos com outros seres vivos e com os fatores não vivos do ambiente, com destaque para as interações que os seres humanos estabelecem entre si e com os demais seres vivos e elementos não vivos do ambiente. Abordam-se, ainda, a importância da preservação da biodiversidade e como ela se distribui nos principais ecossistemas brasileiros (BRASIL, 2018, p. 324)

Dando sequência, o mesmo segue apontando que nos Anos Iniciais “as características dos seres vivos são trabalhadas a partir das ideias, representações, disposições emocionais e afetivas que os alunos trazem para a escola" (BRASIL, 2018, p. 324) e que nos Anos Finais, a partir do

reconhecimento das relações que ocorrem na natureza, evidencia-se a participação do ser humano nas cadeias alimentares e como elemento modificador do ambiente, seja evidenciando maneiras mais eficientes de usar os recursos naturais sem desperdícios, seja discutindo as implicações do consumo excessivo e descarte inadequado dos resíduos. Contempla-se, também, o incentivo à proposição e adoção de alternativas individuais e coletivas, ancoradas na aplicação do conhecimento científico, que concorram para a sustentabilidade socioambiental (BRASIL, 2018, p. 324-325).

Assim, o mesmo vai apresentando a unidade temática e, num segundo momento, enfatiza um outro foco da unidade: o corpo humano. Nele é exposto que o "o corpo humano é um todo dinâmico e articulado, e que a manutenção e o funcionamento harmonioso desse conjunto dependem da integração entre as funções específicas desempenhadas pelos diferentes sistemas que o compõem" (BRASIL, 2018, p. 325). Destaca-se ainda que nele, os aspectos relativos à saúde devem ser compreendidos não somente como "não somente como um estado de equilíbrio dinâmico do corpo, mas como um bem da coletividade, abrindo espaço para discutir o que é preciso para promover a saúde individual e coletiva, inclusive no âmbito das políticas públicas" (idem).

No entanto, o que fica bastante evidente é que as questões relativas a temática da sexualidade já não estão mais inseridas nos Anos Inicias do Ensino Fundamental, sendo 


\section{HORIZONTES - REVISTA DE EDUCACATO}

E-ISSN: $2318-1540$

inclusive, afirmadas no documento que serão apenas evidenciadas (muito brevemente por sinal) nos Anos Finais.

Nos anos finais, são abordados também temas relacionados à reprodução e à sexualidade humana, assuntos de grande interesse e relevância social nessa faixa etária, assim como são relevantes, também, o conhecimento das condições de saúde, do saneamento básico, da qualidade do ar e das condições nutricionais da população brasileira (BRASIL, 2018, p. 325, grifos nosso).

Se fizermos uma busca pela palavra "sexualidade", em todo documento ela só aparece na citação acima e na habilidade EF08CI11 (Selecionar argumentos que evidenciem as múltiplas dimensões da sexualidade humana (biológica, sociocultural, afetiva e ética)) do objeto de conhecimento "sexualidade", totalizando duas menções a palavra.

Assim, embora o documento como um todo, deixasse claro que caberia aos sistemas e redes de ensino, assim como às escolas “incorporar aos currículos e às propostas pedagógicas a abordagem de temas contemporâneos que afetam a vida humana em escala local, regional e global, preferencialmente de forma transversal e integradora" (BRASIL, 2018, p. 19, grifo nosso), o retrocesso referente as temáticas da sexualidade são evidentes em todas as versões propostas seja para o Ensino de Ciências e/ou quaisquer áreas do conhecimento.

Em sua primeira e segunda versões (BRASIL, 2015; 2016) os temas contemporâneos ainda se chamavam de temas integradores.

Os temas integradores dizem respeito a questões que atravessam as experiências dos sujeitos em seus contextos de vida e atuação e que, portanto, intervêm em seus processos de construção de identidade e no modo como interagem com outros sujeitos, posicionando-se ética e criticamente sobre e no mundo nessas interações. Contemplam, portanto, para além da dimensão cognitiva, as dimensões política, ética e estética da formação dos estudantes. Os temas integradores perpassam objetivos de aprendizagem de diversos componentes curriculares, nas diferentes etapas da educação básica (p.16)

Só mesmo a partir da terceira versão (BRASIL, 2017) é que passa a se chamar temas contemporâneos. No entanto, cada versão em sua especificidade propôs temáticas que são contempladas em habilidades dos componentes curriculares, cabendo aos sistemas de ensino e 


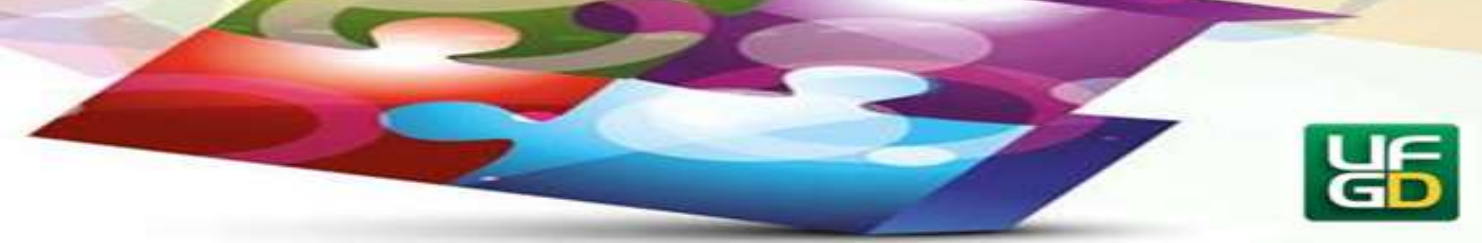

escolas, de acordo com suas especificidades, tratá-las de forma contextualizada e que, são apresentadas a seguir:

Quadro 1 - Temáticas propostas pela BNCC: temas integradores e/ou contemporâneos

\begin{tabular}{|c|c|c|c|}
\hline PRIMEIRA VERSÃO & SEGUNDA VERSÃO & TERCEIRA VERSÃO & QUARTA VERSÃO \\
\hline $\begin{array}{l}\text { - Consumo e educação } \\
\text { financeira; } \\
\text { - Ética, direitos } \\
\text { humanos e cidadania; } \\
\text { - Sustentatibilidade; } \\
\text { - Tecnologias digitais; } \\
\text { - Culturas africanas e } \\
\text { indígenas. }\end{array}$ & $\begin{array}{l}\text { - Economia, educação } \\
\text { financeira e } \\
\text { sustentabilidade; } \\
\text { - Culturas indígenas e } \\
\text { africanas; } \\
\text { - Culturas digitais; } \\
\text { - Direitos humanos e } \\
\text { cidadania; } \\
\text { - Educação ambiental. }\end{array}$ & $\begin{array}{l}\text { - Direitos das crianças } \\
\text { e adolescentes; } \\
\text { - Educação para o } \\
\text { trânsito; } \\
\text { - Preservação do meio } \\
\text { ambiente; } \\
\text { - Educação alimentar e } \\
\text { nutricional; } \\
\text { - Processo de } \\
\text { envelhecimento, } \\
\text { respeito e valorização } \\
\text { do idoso; } \\
\text { - Educação em direitos } \\
\text { humanos; } \\
\text { - Saúde e sexualidade; } \\
\text { - Vida familiar e } \\
\text { social; } \\
\text { - Educação para o } \\
\text { consumo; } \\
\text { - Educação financeira } \\
\text { e fiscal; } \\
\text { - Trabalho, ciência e } \\
\text { tecnologia; } \\
\text { - Diversidade cultural. }\end{array}$ & $\begin{array}{l}\text { - Direitos da criança e } \\
\text { do adolescente; } \\
\text { - Educação para o } \\
\text { trânsito; } \\
\text { - Educação ambiental; } \\
\text { - Educação alimentar e } \\
\text { nutricional; } \\
\text { - Processo de } \\
\text { envelhecimento, } \\
\text { respeito e valorização } \\
\text { do idoso; } \\
\text { - Educação em direitos } \\
\text { humanos; } \\
\text { - Educação das } \\
\text { relações étnico-raciais } \\
\text { e ensino de história e } \\
\text { cultura afro-brasileira, } \\
\text { africana e indígena; } \\
\text { - Saúde, vida familiar } \\
\text { e social; } \\
\text { - Educação para o } \\
\text { consumo; } \\
\text { - Educação financeira } \\
\text { e fiscal; } \\
\text { - Trabalho, ciência e } \\
\text { tecnologia; } \\
\text { - Diversidade cultural. }\end{array}$ \\
\hline
\end{tabular}

Fonte: o autor, com base na BNCC (BRASIL, 2015, 2016, 2017, 2018, grifo nosso)

Entretanto, numa tentativa de erros e acertos, talvez mais erros que acertos, a sexualidade só é evidenciada na terceira versão. No entanto, tão logo que a mesma foi apresentada a bancada religiosa do Congresso Nacional já se deu ao trabalho e não mediram esforços para sua retirada. No entanto, não fora só com a palavra sexualidade, mas todas as palavras que compõem discussões necessárias da área, tais como gênero, orientação sexual e identidade de gênero.

Soares, Santos e Pereira (2018) até apontam para uma legitimação quanto a abordagem da sexualidade nos currículos, já que o termo mesmo excluído dos temas contemporâneos ainda 


\section{HORIZONTES - REVISTA DE EDUCACATO}

E-ISSN $: 2318-1540$

aparece na versão final, mesmo que duas vezes no Ensino de Ciências e nos Anos Finais do

Ensino Fundamental, mas reforçam para uma preocupação frente às questões de gênero.

[...] Como abordar as múltiplas dimensões da sexualidade, as IST, o uso de contraceptivos sem destacar as desigualdades, os obstáculos e as hierarquias de gênero? Suprimir esses temas da BNCC reflete uma visão conservadora, como uma ameaça à chamada "família tradicional", mas acima de tudo desconsidera o acúmulo de debates, pesquisas e conquistas dos movimentos sociais em busca da equidade de direitos.

Por outro lado, a sexualidade é apresentada em associação com doenças, violência e gravidez, evidenciando um distanciamento entre a orientação proposta e a vivência dos estudantes (SOARES, SANTOS e PEREIRA, 2018, p. 11).

Contudo, percebe-se cada vez mais um distanciamento do conceito de sexualidade, aproximando-o sempre, como as autoras afirmam a uma "associação com doenças, violência e gravidez" (idem). Pensar sobre a sexualidade, mesmo nos Anos Iniciais do Ensino Fundamental é ir muito além disso.

A sexualidade humana, mais do que o ato sexual e a reprodução, abrange as pessoas, seus sentimentos e relacionamentos. Implica aprendizados, reflexões, planejamentos, valores morais e tomadas de decisão. A sexualidade é uma energia forte e mobilizadora, uma dimensão da expressão do ser humano em relação consigo mesmo e com o outro, lugar do desejo, do prazer e da responsabilidade.

[...] Conhecer a sexualidade não significa aprender a estrutura dos genitais. Educação Sexual centrada na genitalidade advém de uma educação que disciplina, organiza e concentra o prazer nos genitais; assim procedendo, anestesia o resto do corpo (CAMARGO e RIBEIRO, 2003, p. 50)

No entanto, mesmo que o documento trouxesse evidências de um trabalho mais biológico nessa quarta versão, e por se tratar de uma abordagem para o Ensino de Ciências, Ribeiro (1996) nos alerta que não é possível

construir primeiramente um corpo e somente depois um corpo sexuado. Os materiais significantes para essa construção provêm de duas ordens: do organismo e da cultura. No organismo, os imperativos biológicos básicos que diferenciam homens e mulheres são o fecundar para o homem e o menstruar, gestar e amamentar para as mulheres. As outras diferenças são atribuídas socialmente e variam de acordo com a época, o local e a cultura (p. 23, grifos nosso). 


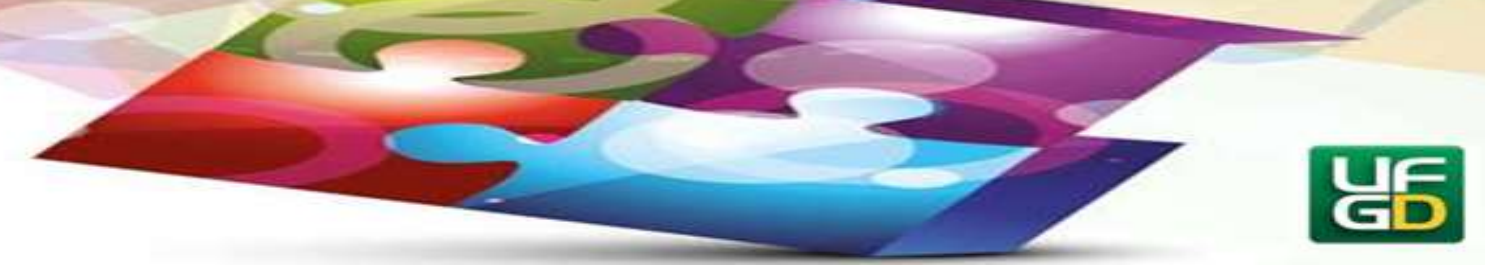

Assim, considerando a sexualidade uma dimensão exclusivamente humana (NUNES, 1996; FIGUEIRÓ, 2014; SILVA, 2015) e que a mesma não se limita apenas a uma abordagem biológica e trabalhada de forma fragmentada, mas sim em sua totalidade e numa construção social, Werebe (1998) vem afirmar, que é preciso ainda, criar condições para que as crianças e os jovens possam exprimir suas dúvidas, inquietações e curiosidades a respeito da sexualidade em geral e da sua própria. No entanto, da maneira como é apresentado no documento, em nenhum momento essa compreensão fica evidente.

Se observamos o quadro abaixo, da unidade temática "vida e evolução" do $1^{\circ}$ ano, percebemos que as habilidades apresentadas poderiam direcionar o trabalho do professor para a temática da sexualidade.

Quadro 2-Ciências: $1^{\circ}$ ano

\begin{tabular}{|l|l|}
\hline Objetos de Conhecimento & Habilidades \\
\hline Corpo humano & $\begin{array}{l}\text { (EF01CI02) Localizar, nomear e representar graficamente (por } \\
\text { meio de desenhos) partes do corpo humano e explicar suas } \\
\text { funções. } \\
\text { (EF01CI03) Discutir as razões pelas quais os hábitos de higiene do } \\
\text { corpo (lavar as mãos antes de comer, escovar os dentes, limpar os } \\
\text { olhos, o nariz e as orelhas etc.) são necessários para a manutenção da } \\
\text { saúde. } \\
\text { (EF01CI04) Comparar características físicas entre os colegas, } \\
\text { reconhecendo a diversidade e a importância da valorização, do } \\
\text { acolhimento e do respeito às diferenças. }\end{array}$ \\
\hline
\end{tabular}

Fonte: BNCC (BRASIL, 2018)

As habilidades, segundo a BNCC “expressam as aprendizagens essenciais que devem ser asseguradas aos alunos nos diferentes contextos escolares” (BRASIL, 2018, p. 29). E elas seguem uma estrutura, apresentada com o exemplo da habilidade a seguir: "(EF01CI02) Localizar, nomear e representar graficamente (por meio de desenhos) partes do corpo humano e explicar suas funções".

Seguindo a estrutura proposta pela BNCC e pelo nosso exemplo, o Localizar, nomear e representar são verbos que explicitam os processos cognitivos envolvidos na habilidade. $\mathrm{Ou}$ seja, a criança localiza, nomeia e ainda representa. Já o graficamente (por meio de desenhos) partes do corpo humano é um complemento do verbo, que explicita o objeto de conhecimento mobilizado na habilidade. Aqui no caso, a criança irá precisar desenhar. E por último, e explicar 


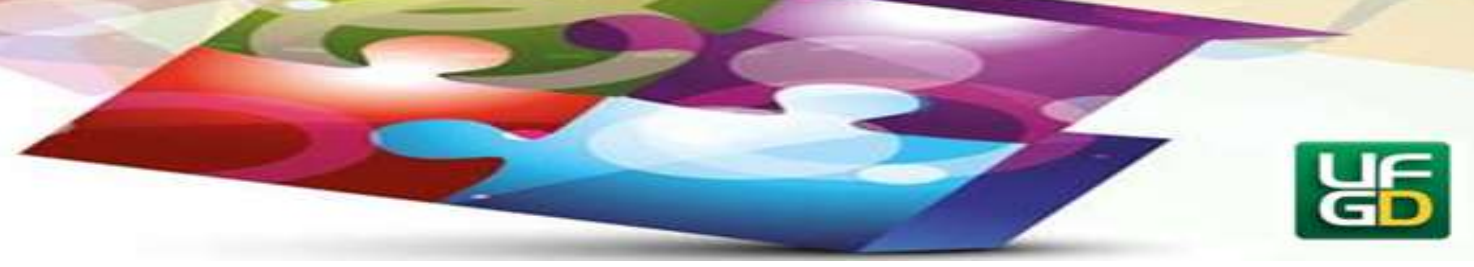

suas funções é um modificador do verbo ou no nosso caso, do complemento do verbo, que explicita o contexto e/ou uma maior especificação da aprendizagem esperada. Que no nosso caso, além de desenhar as partes do corpo, a criança precisa ainda explicar cada uma de suas funções.

Os modificadores devem ser entendidos como a explicitação da situação ou condição em que a habilidade deve ser desenvolvida, considerando a faixa etária dos alunos. Ainda assim, as habilidades não descrevem ações ou condutas esperadas do professor, nem induzem à opção por abordagens ou metodologias. Essas escolhas estão no âmbito dos currículos e dos projetos pedagógicos, que, como já mencionado, devem ser adequados à realidade de cada sistema ou rede de ensino e a cada instituição escolar, considerando o contexto e as características dos seus alunos (BRASIL, 2018, p. 30).

Que interessante seria se o professor aproveitasse por exemplo uma atividade que elencasse esta habilidade para então falar sobre os nomes científicos dos órgãos sexuais masculino e feminino e falar sobre gênero também, umas vez que, será quase impossível que nenhuma criança desenhe um pênis ou uma vulva a partir dessa habilidade, pois conforme aponta Ribeiro (1996) "quando a criança é solicitada a desenhar uma pessoa, na maioria das vezes ela faz o desenho representando o próprio sexo" (p. 111). Com isso, estaríamos proporcionando

[...] para que pudessem, além de aprender cada parte de seu próprio sistema, aprender sobre o corpo do outro, a fim de se trabalhar o respeito, a valorização do corpo, assim como, principalmente, aprender que para a menina, ter uma vulva é tão importante quanto ter um pênis para o menino, sem relação de poder entre os órgãos genitais. Cada um, com suas características físicas e biológicas, é importante. Isto possibilitaria um diálogo essencial nas questões de gênero (SILVA, 2015, p. 33).

Para Ribeiro (1996, p. 40), quando se é proporcionado também à criança a oportunidade de discutir diversos assuntos "relacionados com o próprio corpo, sob diferentes enfoques e utilizando materiais variados, enriquecerá sobremaneira suas experiências".

$\mathrm{Na}$ habilidade comparar características físicas entre os colegas, reconhecendo a diversidade e a importância da valorização, do acolhimento e do respeito às diferenças, se não houvesse uma discussão para além de exemplos tão corriqueiros como ele é alto e ele é baixo, mas que os professores também elucidassem uma discussão para além dessas 


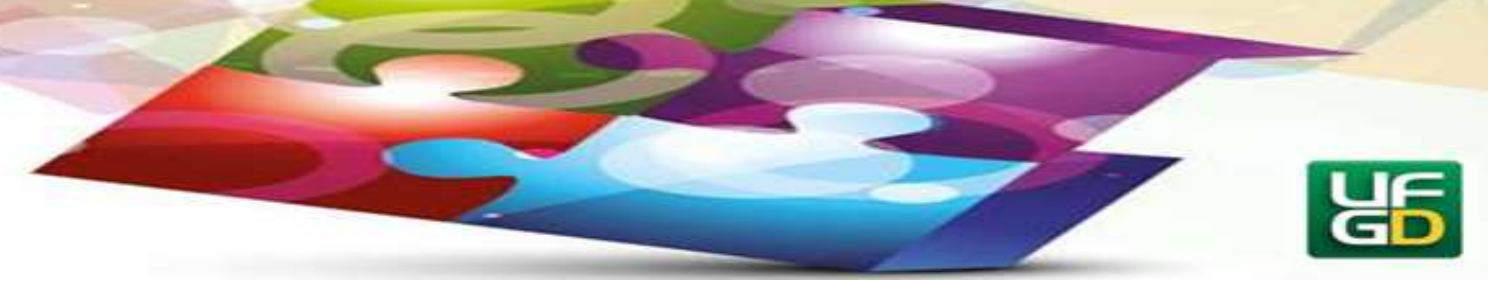

características físicas, tais como: menino é mais forte que menina? Menino não chora? Menino que chora é mulherzinha? Isto por si só, evidenciaria uma experiência incrível em sala de aula tanto para o professor quanto para seus alunos.

Para Silva (2015), ao se propor essas discussões “a escola assume seu compromisso numa educação igualitária, ela passa a fazer parte de um processo muito importante de aceitar uma mudança de postura, o que a permitirá buscar alternativas de mudanças para esses tratamentos inadequados, muitas vezes discriminatórios" (p.33). Com isso, os verbos comparar e reconhecer que explicitam os processos cognitivos envolvidos na habilidade seriam desenvolvidos a partir do objeto de conhecimento mobilizado (a diversidade) e ainda possibilitariam chegar ao modificador do complemento do verbo (e a importância da valorização, do acolhimento e do respeito às diferenças), que explicita ainda mais o contexto como um todo.

Já para a habilidade discutir as razões pelas quais os hábitos de higiene do corpo (lavar as mãos antes de comer, escovar os dentes, limpar os olhos, o nariz e as orelhas etc.) são necessários para a manutenção da saúde seria quase que acreditar em contos de fada se o professor fosse além do que é apresentada. Um exemplo, se o mesmo abordasse sobre a higiene também dos genitais masculinos e femininos numa linguagem acessível às crianças, já que muitas vezes, essa prática não se é ensinada em casa e muitos homens já adultos, por exemplo, desconhecem os cuidados e hábitos de higiene que devem ter com seu próprio pênis. Fato este é o número crescente de câncer no pênis e o motivo principal: falta de higiene ${ }^{2}$.

Dando sequência, nos $2^{\circ}$ e $4^{\circ}$ anos, nenhum objeto de conhecimento com suas respectivas habilidades condicionam para um trabalho na área da sexualidade, principalmente por tratarem mais especificamente sobre plantas, cadeias alimentares simples e microrganismos.

No quadro abaixo, são apresentados os objetos de conhecimento do $3^{\circ}$ ano que poderiam brevemente (e que no documento, não seriam estes os objetivos) conduzir a este trabalho, porém, como não é explicitamente apresentado, poderão passar despercebidos pelo professor, o condicionando ao trabalho pontual tal qual estão descritos nas habilidades.

Quadro 3 - Ciências: $3^{\circ}$ ano

${ }^{2}$ DESIDÉRIO, Ricardo. Lave o pinto. Disponível em <https://youtu.be/gG_LZvtF3Fg>. Acesso em: 16out2019. 


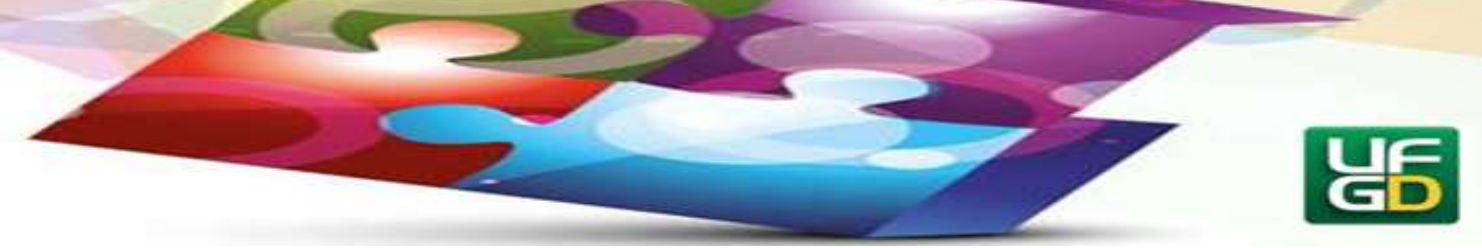

\begin{tabular}{|l|l|}
\hline $\begin{array}{l}\text { Características } \\
\text { desenvolvimento dos animais }\end{array}$ & $\begin{array}{l}\text { (EF03CI04) Identificar características sobre o modo de vida (o que } \\
\text { comem, como se reproduzem, como se deslocam etc.) dos animais } \\
\text { mais comuns no ambiente próximo. } \\
\text { (EF03CI05) Descrever e comunicar as alterações que ocorrem desde } \\
\text { o nascimento em animais de diferentes meios terrestres ou aquáticos, } \\
\text { inclusive o homem. } \\
\text { (EF03CI06) Comparar alguns animais e organizar grupos com base } \\
\text { em características externas comuns (presença de penas, pelos, } \\
\text { escamas, bico, garras, antenas, patas etc.). }\end{array}$ \\
\hline
\end{tabular}

Fonte: BNCC (BRASIL, 2018)

Na habilidade (EF03CI05) descrever e comunicar as alterações que ocorrem desde o nascimento em animais de diferentes meios terrestres ou aquáticos, inclusive o homem seria possível que alguma criança questionasse sobre a origem de seu nascimento com a "assustadora" pergunta: de onde eu vim? Já que a habilidade propõe descrever e comunicar as alterações que ocorrem desde o nascimento.

Já no $5^{\circ}$ ano (quadro 4), o Ensino de Ciências na BNCC surpreendentemente exclui o sistema reprodutor masculino e feminino dos Anos Iniciais. Abordam-se apenas sobre os sistemas digestório, respiratório e circulatório, não mais evidenciando o corpo humano como um todo, mas fragmentado.

Quadro 4-Ciências: $5^{\circ}$ ano
\begin{tabular}{|l|l|}
\hline $\begin{array}{l}\text { Nutrição do organismo } \\
\text { Hábitos alimentares }\end{array}$ & (EF05CI06) Selecionar argumentos que justifiquem por que os \\
$\begin{array}{l}\text { Integração entre os sistemas } \\
\text { digestório, respiratório e e } \\
\text { circulatório }\end{array}$ & $\begin{array}{l}\text { sistemas digestório e respiratório são considerados corresponsáveis } \\
\text { pelo processo de nutrição do organismo, com base na identificação } \\
\text { das funções desses sistemas. } \\
\text { (EF05CI07) Justificar a relação entre o funcionamento do sistema } \\
\text { circulatório, a distribuição dos nutrientes pelo organismo e a } \\
\text { eliminação dos resíduos produzidos. } \\
\text { (EF05C108) Organizar um cardápio equilibrado com base nas } \\
\text { características dos grupos alimentares (nutrientes e calorias) e nas } \\
\text { necessidades individuais (atividades realizadas, idade, sexo etc.) para } \\
\text { a manutenção da saúde do organismo. } \\
\text { (EF05CI09) Discutir a ocorrência de distúrbios nutricionais (como } \\
\text { obesidade, subnutrição etc.) entre crianças e jovens a partir da análise } \\
\text { de seus hábitos (tipos e quantidade de alimento ingerido, prática de } \\
\text { atividade física etc.). }\end{array}$ \\
\hline
\end{tabular}

Fonte: BNCC (BRASIL, 2018)

Com isso, evidentes retrocessos marcam mais uma vez o trabalho com a temática sexualidade nas escolas, não condicionando para efetivos trabalhos em sala de aula. Só nos 


\section{HORIZONTES - REVISTA DE EDUCACATO}

e-ISSN: 2318-1540

resta saudosamente lembrarmos dos PCN (BRASIL, 1997) que sem dúvidas, ainda representa um marco histórico e oficial da Educação Sexual nas escolas. E como nos aponta Silva (2015)

tão evidente quanto necessário é nos lembrarmos de um documento nacional, os Parâmetros Curriculares Nacionais (PCN), conjunto de propostas educativas elaboradas a partir de uma bancada de profissionais de diversas áreas publicado pelo Ministério da Educação e do Desporto no ano de 1997 (BRASIL, 2001). Além das diversas áreas do conhecimento, tais como Língua Portuguesa, Matemática, Língua Estrangeira, História, Geografia, Ciências Naturais, Arte e Educação Física, os PCN, visando trabalhar temas sociais de modo transversal a essas disciplinas curriculares, apresentaram também volumes que tratavam dos seguintes temas: ética, saúde, meio ambiente, orientação sexual e pluralidade cultural (SILVA, 2015, p. 20).

No entanto, numa tentativa de apresentar os atuais temas contemporâneos (BRASIL, 2018), que poderiam nos direcionar a esta temática em sala de aula, somos efetivados a partir da versão final com sua exclusão. Isto por si só nos reflete a um conservadorismo atual e tão arraigado em nossa sociedade. Uma sociedade que vive "uma época sexualmente interessante, o que significa uma cultura que consegue ser ao mesmo tempo hipersexualizada e conservar suas esporas puritanas em proporções exatamente iguais" (KIPNIS, 2012, p.20).

\section{Considerações finais}

No entanto, frente a um documento que exclui a temática da sexualidade, a resistência é uma ação necessária e fundamental para um efetivo trabalho de Educação Sexual com crianças nas escolas. Afinal, conforme nos aponta Silva (2015), ela

é hoje uma necessidade a ser efetivada tanto nas discussões políticas, quanto nas ações e concretização de sua prática. Ao dizer Educação Sexual estamos nos referindo a toda ação contínua, em um processo de interação humana pelo qual, inserido em uma cultura, uma história e uma política, nos leva a pensar na construção de um sujeito ativo frente às informações, aos desejos, às necessidades básicas sobre seu corpo, seu funcionamento e organização. Assim, tal sujeito pode dialogar, ter voz ativa e poder expressar suas opiniões, respeitando as opiniões do outro e significativamente percebendo a sexualidade como algo positivo em sua vida, sem medos, tabus e/ou receios em poder/querer aprender sobre tudo que se passa a sua volta durante toda sua vida (p. 20). 


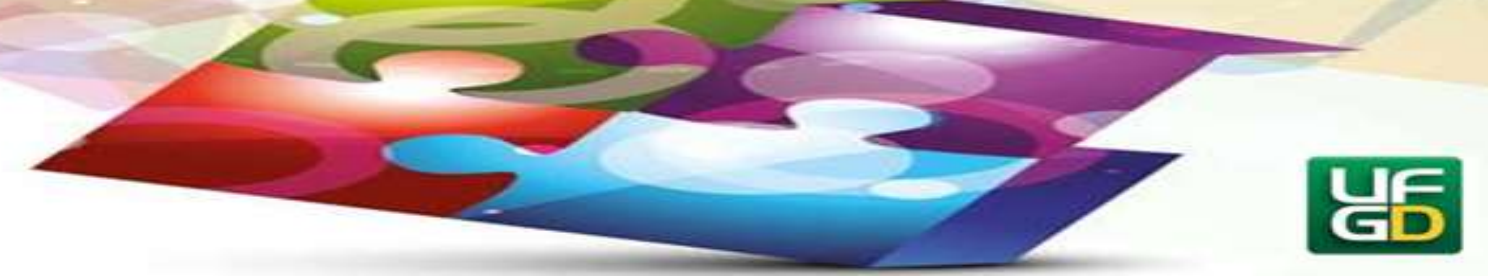

Contudo, um trabalho planejado se faz necessário e inicialmente, precisamos ter consciência de sua necessidade de implantação, o que nos conduzirá para um trabalho efetivo e sistemático de Educação Sexual nas escolas. Para tanto, reforço sua importância na compreensão das dimensões técnica, estética, política e ética (SILVA, 2015).

A dimensão técnica, refere-se a necessidade de uma preparação formal, sistematizada e científica quanto à formação continuada na área, fortalecendo assim o domínio nos conteúdos básicos de sexualidade e Educação Sexual. Ou seja, é preciso formação, conhecimento e muita leitura na área. Já na dimensão estética, a mesma se refere à sensibilidade e a beleza da sexualidade, não mais como algo feio, sujo e vulgar. Cabendo a nós, educadores, ressignificarmos essa visão negativa da sexualidade para uma vivência positiva e saudável da mesma, pois geralmente o não trabalhar com a temática está sempre relacionado a um posicionamento desfavorável da mesma, sem ao menos compreender a si mesma e a própria sexualidade que ainda é permeada por crenças e tabus.

Em sua dimensão política, devemos assumir nosso compromisso quanto à participação ativa frente à luta na construção de uma Educação Sexual emancipada. Mesmo frente a tantos obstáculos, precisamos ser resistência e acreditar que esse trabalho é fundamental para nossas crianças. E por fim, a dimensão ética, que além do nosso compromisso já assumido, deve nos levar sempre a questionamentos sob o porquê e para que a ensinamos, possibilitando o planejar e replanejar de nossas ações constantemente, possibilitando assim diálogos tão necessários nesse campo do conhecimento.

\section{Referências bibliográficas}

BRASIL. Ministério da Educação. Base Nacional Comum Curricular: Educação é a base. Brasília: MEC, 2018.

. Ministério da Educação. Base Nacional Comum Curricular. Terceira versão revista. Brasília: MEC, 2017.

- Ministério da Educação. Base Nacional Comum Curricular. Segunda versão

revista. Brasília: MEC, 2016. 


\section{HORIZONTES - REVISTA DE EDUCACATO}

e-ISSN: $2318-1540$

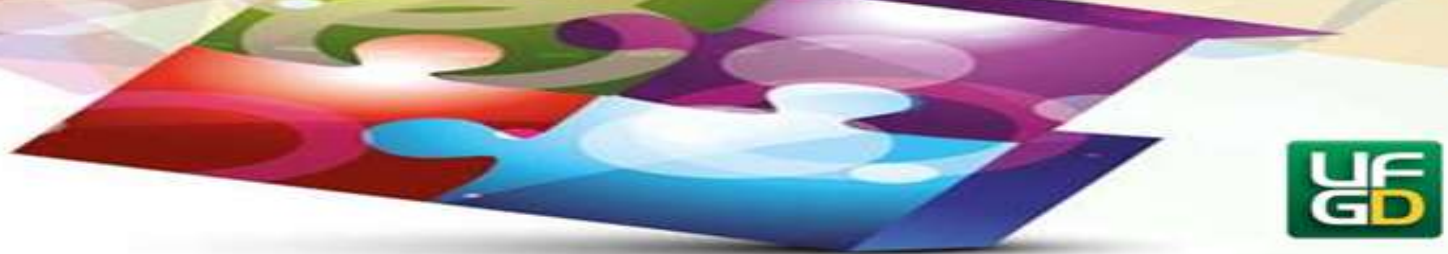

Ministério da Educação. Base Nacional Comum Curricular. Apresentação.

Brasília: MEC, 2015.

Parâmetros Curriculares Nacionais. Brasília: MEC-SEF, 1998.

CAMARGO, Ana Maria Faccioli de; RIBEIRO, Claudia. Sexualidade(s) e infância(s): a sexualidade como um tema transversal. São Paulo: Editora Moderna, 2003.

DELIZOICOV, Demétrio; ANGOTTI, José André; PERNAMBUCO, Marta Maria. Ensino de Ciências: fundamentos e métodos. São Paulo: Cortez, 2009.

FIGUEIRÓ, Mary Neide Damico. Formação de educadores sexuais: adiar não é mais possível. 2 ed. Londrina, PR: Eduel, 2014.

KIPNISI, Laura. Contra o amor. Tradução Ryta Vinagre. $3^{\text {a }}$ ed. Rio de Janeiro: Record, 2012.

NASCIMENTO, Flávio; FERNANDES, Hylio Laganá; MENDONÇA, Viviane Melo de (2010). Ensino de Ciências no Brasil: História, formação de professores e desafios atuais. Revista HISTEDBR [On-line] 39, 225- 249.

NUNES, César Aparecido. Filosofia, sexualidade e educação: As relações entre os pressupostos ético-sociais e histórico-culturais presentes nas abordagens institucionais sobre educação sexual escolar. Tese de doutorado em Educação. Campinas: Unicamp, 1996.

RIBEIRO, Claudia. A fala da criança sobre sexualidade humana: o dito, o explícito e o oculto. Campinas: Mercado de Letras, 1996

SILVA, Ricardo Desidério. Educação Audiovisual da Sexualidade: olhares a partir do Kit Anti-Homofobia. 2015, 144 f. Tese (Doutorado em Educação Escolar). Faculdade de Ciências e Letras, Universidade Estadual Paulista, Araraquara-SP, 2015.

SOARES, Zilene Moreira Pereira; SANTOS, Nathany Ribeiro Lima dos; PEREIRA, Sara. Documentos curriculares oficiais assegurando a abordagem de gênero e sexualidade para a educação básica: um olhar para o ensino de ciências.. In: V Simpósio Gênero e Políticas Públicas, 2018, Londrina - PR. Anais V Simpósio Gênero e Políticas Públicas, 2018.

WEREBE, Maria José Garcia. Sexualidade, Política, Educação. Campinas, SP: Autores Associados, 1998.

Enviado: 09/06/2020

Aceito: $23 / 06 / 2020$ 